\title{
Intute: Law - finding the best of the Web for Law
}

Heather Memess, Intute Law Project Officer, Institute of Advanced Legal Studies and

Steve Whittle, Information Systems Manager, Institute of Advanced Legal Studies

Intute http://www.intute.ac.uk/ is the UK's gateway to high quality information sources on the Internet. The service was launched in July 2006 as the new face of the Resource Discovery Network (RDN) a free online service many librarians and researchers will remember as the national gateway to learning, teaching and research resources on the Internet. The name 'Intute' is a combination of 'Internet' and 'tutorial' and is intended to convey the experiences of guided learning and online resource discovery.

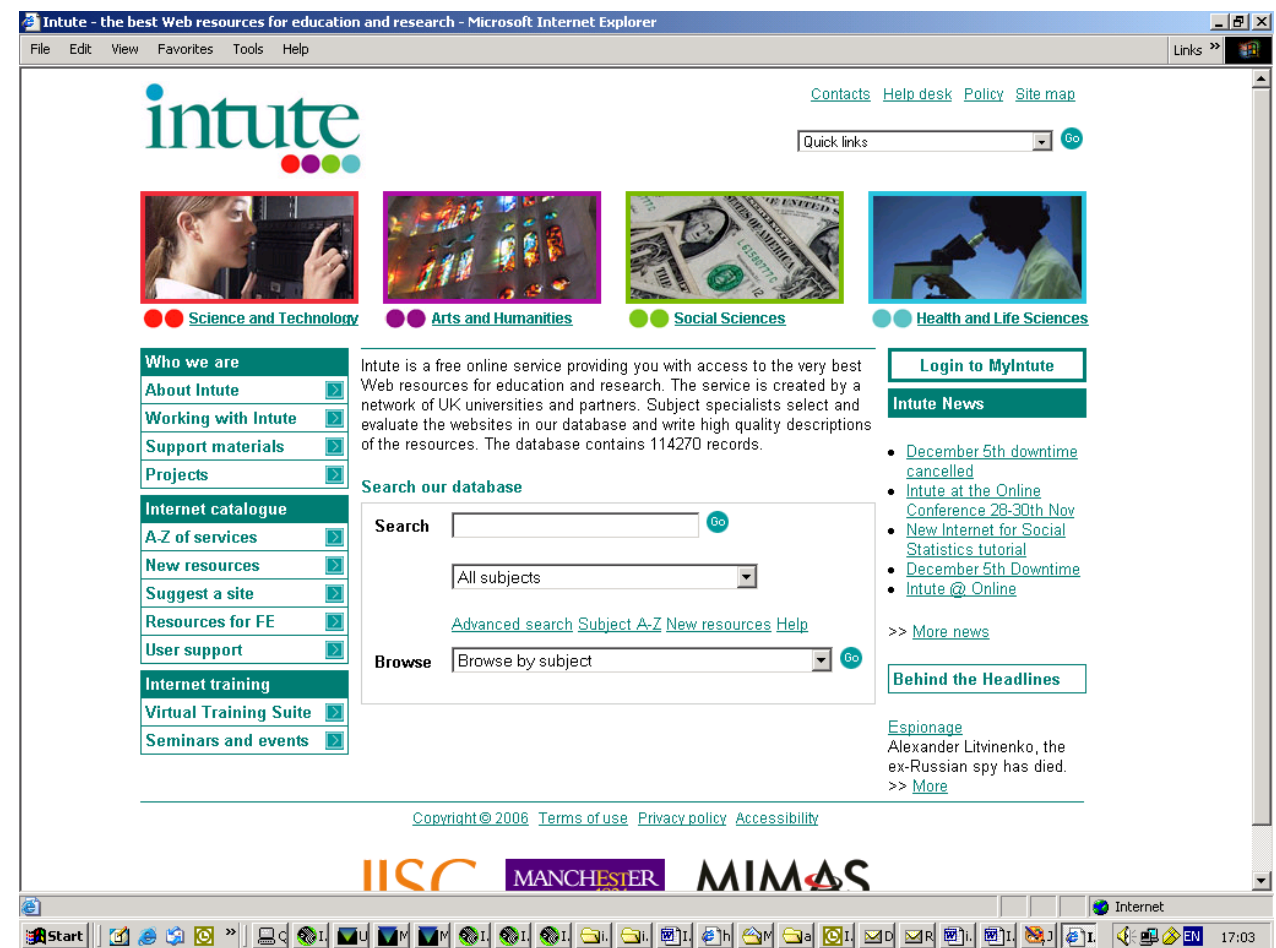

\section{Background and development}

Intute continues the work of the RDN, providing access to the best web resources, but additionally offers a range of value-added services. Intute is hosted by MIMAS at The University of Manchester, and is a consortium involving 7 UK universities: the University of Birmingham, the University of Bristol, Heriot Watt University, the University of Manchester, Manchester Metropolitan University, the University of Nottingham and the University of Oxford, supported by 70 partner institutions providing subject expertise and advice (including for Law, the Institute of Advanced Legal Studies, University of London). The service is funded by the Joint Information Systems Committee (JISC), with support from the Arts and Humanities Research Council (AHRC), and the Economic and Social Research Council (ESRC). 
The RDN was organised into eight subject-based information gateways (or hubs) each maintained on separate databases and servers, these included: Artifact (arts and creative industries), EEVL (engineering, maths and computing), BIOME (health, medicine and life sciences), Humbul (humanities) and SOSIG (social science, business and law) - familiar to librarians and researchers in these fields. With the launch of Intute the hubs have been reorganised into four subject gateways: Science Engineering and Technology, Arts and Humanities, Social Sciences, and Health and Life Sciences - all on a combined database offering the benefits of a consistent search interface, freely accessible from the Intute homepage at http://www.intute.ac.uk/.

\section{Aims of the service}

Intute continues the UK academic community's response to an ever-increasing amount of material on the Internet and ongoing researcher preference for web-based sources. The service is designed to complement other popular search tools, the search engines we use everyday, with a catalogue of quality evaluated site profiles. Intute aims particularly to support work at Higher Education and Further Education levels but also has a public service role. The original reasons for establishing the subject gateways- the need for relevant, high quality, authoritative information- still remain. So whilst the look of Intute is very different to the old RDN, and now includes a colourful homepage with photographs and colour-coded entry points to the different subject areas, the essential purpose of Intute remains the same as that of its predecessor - to provide an Internet catalogue of high quality web resources hand picked and evaluated by subject specialists and librarians. The new name is an indication that the attributes of the service, in terms of resource selection and evaluation, also promote the skills needed to aid effective Internet research at all levels.

Intute: Law - (http://www.intute.ac.uk/socialsciences/law/) Intute: Social Sciences, which has replaced SOSIG (the Social Science Information Gateway), includes a dedicated gateway for law edited by staff at the Institute of Advanced Legal Studies (IALS) Library and the University of Bristol Law Library. We select the best online resources of interest to law lecturers, researchers and students to include in the catalogue of quality resources supporting law. Resources covering UK, foreign, comparative and international law, including a full range of jurisdictions and legal topics from around the world, are quality checked by the section editors. Intute records include short profiles of key sites, highlighting the most useful aspects, enabling researchers to quickly identify the most relevant sources of legal information. A range of different resource types is represented on Intute: Law including primary materials (legislation, case law, treaties), secondary sources (journals, books), government websites, organisations, databases, academic sites, law firm sites (companies), bibliographic materials and resource guides. 


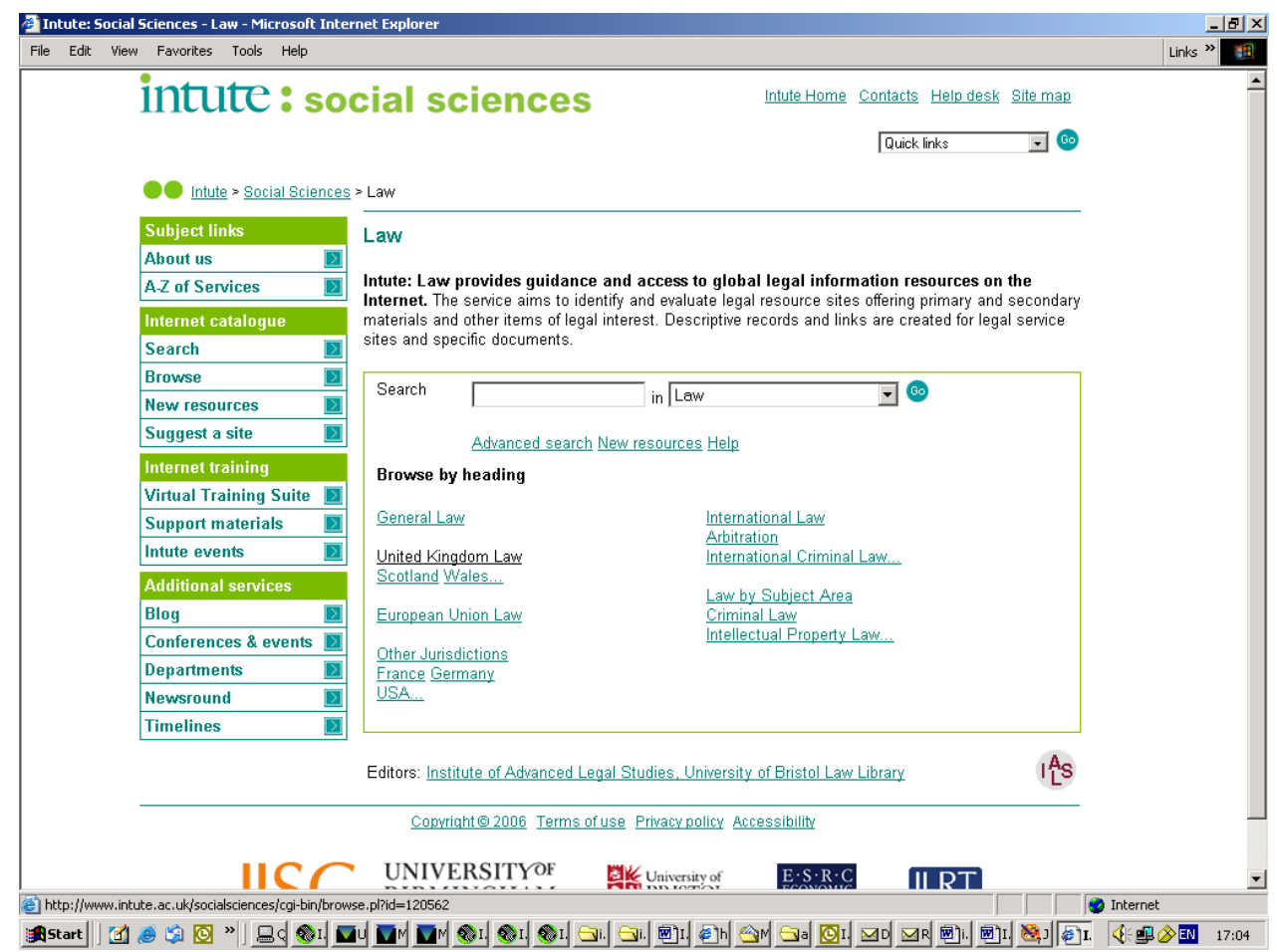

\section{Browsing and Searching on Intute}

A menu on the left of the Intute: Law screen gives quick access to search and browse functions, support materials and additional services. It is possible to search the whole of Intute across all subject areas or to focus on individual subjects and sub-sections. A search on the full catalogue aids inter-disciplinary work, enabling researchers to find law materials in other contexts such as business, government and politics. Searching can be done via a simple keyword search box or by using the advanced search form, which enables you to construct queries specifying fields to be searched, subject area and resource type. Browsing from the Law page takes you to the following categories: General Law, UK Law, European Union Law, Other Jurisdictions, International Law and Law by Subject Area. Selecting any of these will take you to another list of sub-categories. For example, Other Jurisdictions provides you with a list of countries and the number of resources available for each. Below this list are resources dealing generally with a range of jurisdictions arranged alphabetically. In this way the service offers options to support different stages of research - you can browse to gather materials and see what is out there or you can search to pinpoint specific items.

\section{Viewing and filtering results}

To aid access, the resources presented in results lists can be arranged and re-ordered in a number of ways. Search results can be sorted alphabetically by title or by relevance to the search terms employed (default option). Browse results can be sorted alphabetically by title (default option) or by date added to the service (most recent first). The first records in the results list are those labeled 'Editor's Choice' which are sites of particlular value and importance as identified by the section editors.

The results of browsing on Intute can be further refined by specifying resource type. These include bibliographies, companies, governmental bodies, journals, organisations and societies, research projects and resource guides. Special law categories are used to help locate the main forms of primary legal literature: 
legislation, law reports, digests and treaties. A filter option allows a results list to be limited to any of these resource types.

\section{Intute Records - evaluative site profiles}

The browse list presents records in full with the option to link directly to the resource via the title, the URL or the $\odot$ button, or to view more details about the resource through the Details link. The full record gives the site title (which also acts as a link to the site itself), a description of the resource, a list of keywords assigned to the resource, information about country of origin, site format, languages, classification codes and site url. Evaluative site profiles are a distinguishing feature of Intute, providing researchers with information about the contents and coverage of a site that might otherwise be missed - such as selected full text Cayman Islands legislation on a law firm website. Every word of the description is available to a search on the system - helping you uncover hard to find material from less likely places.

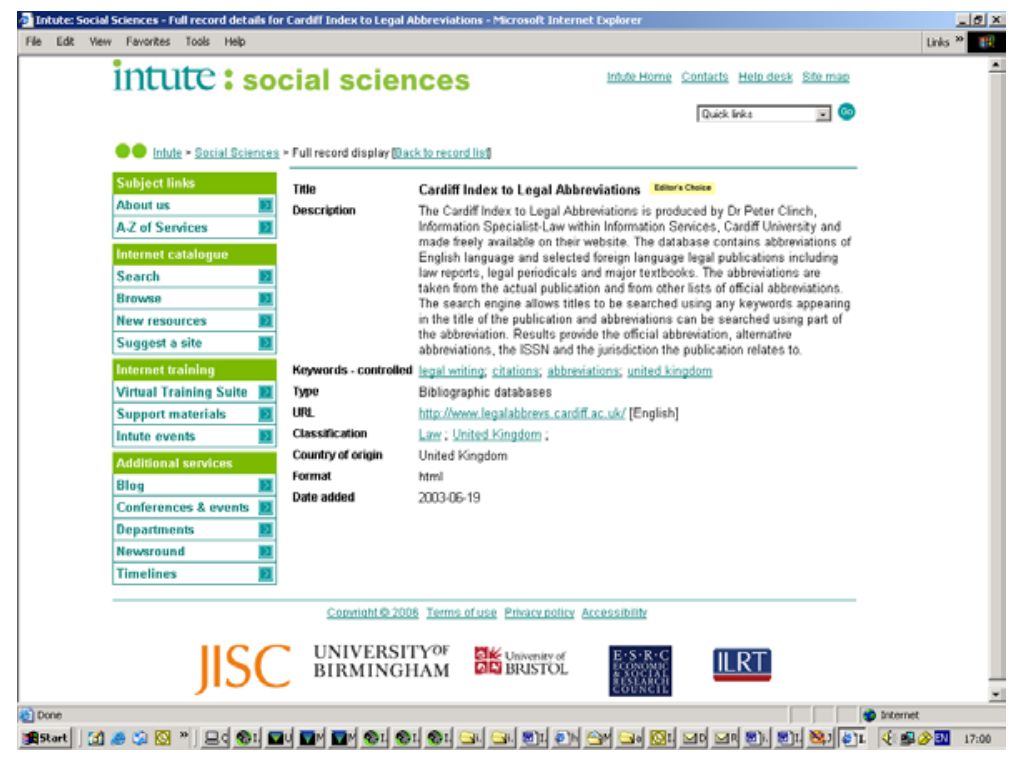

It is also possible to view the most recent resources added to the database including all new additions or just those in the subject area you are interested in.

\section{Harvester - searching more widely}

An additional search engine on the service called the Harvester complements the catalogue of quality resources and can be used to extend your search beyond the Intute catalogue. The Harvester indexes pages from the quality checked websites listed in the Intute catalogue. Searches carried out using the Harvester will return a larger number of 'hits' linking to additional materials sourced from quality-checked sites. If you need a wider pool of resources to work on this is a useful additional tool. A Harvester search is run automatically in parallel with a search on the Intute Internet Resource Catalogue and a link to the results with an indication of the number of Harvester hits is offered on the Intute results screen.

\section{Additional Intute Services and Functionality}

While the Internet Catalogue remains at the heart of Intute, a number of additional, value-added services are also offered and can be accessed from any page on the site. These include training and support materials, details of conferences and events which 
can be browsed by subject or searched by keyword, contact details for all social science departments in UK higher education institutions and social science news.

\section{MyIntute - personalisation and alerting}

One of the new features of Intute currently being developed is the MyIntute service. This personalisation tool enables you to create your own set of records from resources you have searched or browsed on Intute in the usual way. Records can be tagged and saved before being emailed or exported to another website - as part of a personal Internet resource bibliography or reading list for example, or as a reliable set of links for an academic web page.

You can mark records for saving in a search or browse session by using the tick button at the right of each record. The record is then highlighted to indicate it has been selected for saving. The number of records you have marked for saving is shown in the MyIntute box on the left of the screen. You can review records you have marked by clicking on the "collect records" link and then delete any records you don't require from this list. You may then export the saved records to your own web pages. Click on "Save as HTML" and copy and paste the code provided into your web page. Or you may save the records as plain text for re-use elsewhere.

When you are logged into MyIntute you can save your searches and receive email alerts whenever new records have been added which match your search terms. Similarly you can select subject areas of interest and receive email alerts when new records are added for these subjects. You can register your details freely on the service to access the MyIntute features.

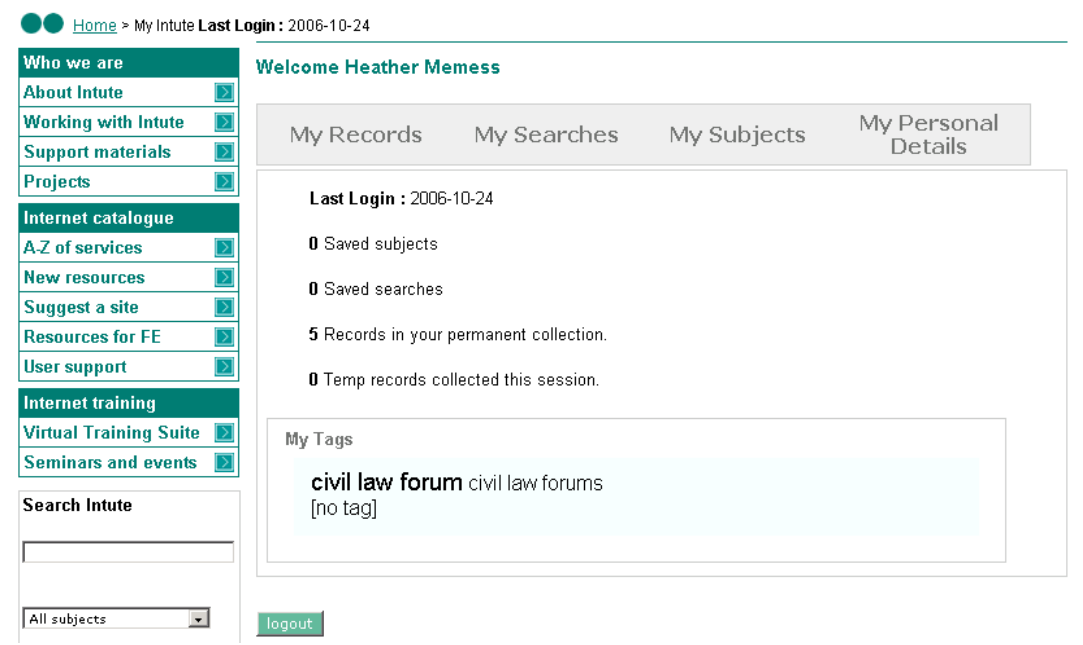

\section{Internet Training}

As its name implies, Intute has a training dimension and is designed to help raise awareness of information literacy, Internet research and legal research skills. Selection and evaluation are key characteristics of Intute and key skills to promote amongst its user community. A growing range of training materials is offered by the service, designed to help locate the Internet in the legal research process, map research tasks to relevant Internet research resources, and encourage critical thinking about the different ways that the Internet can come into play to aid that work. 


\section{Intute Law workbooks}

Intute Law workbooks have been prepared by Steve Whittle and David Gee at IALS Library and made freely available on the site to help in the teaching of legal information skills and Internet awareness. The workbooks are designed to introduce the service, aiding practical workshop sessions as well as supporting self-paced learning. There is a general Law workbook and a workbook focusing on Foreign, Comparative and International law. The workbooks contain examples and exercises to help explore the wealth of legal materials available on the Internet, with suggestions on how to make full use of Intute: Law for law teaching, study and research. The workbooks look at the range of materials included in and referenced through Intute, highlight Intute features and show how Intute can help academic and professional legal researchers filter the mass of Internet information, making it easier to find useful sites for a given jurisdiction or legal subject area. Both workbooks are MS Word documents that may be downloaded from the service and freely adapted for local training needs. The Intute Law workbook and Intute Foreign, Comparative and International Law workbook are available from http://www.intute.ac.uk/socialsciences/support.html and from the IALS website http://ials.sas.ac.uk/library/intute/intutelaw.htm

In addition, an Intute: Social Sciences guide card has been published to raise awareness of the service and aid in its use. Printed copies are available on request and a PDF version is available from the Intute Support Materials page. A booklet introducing the "Best of the Web for Law" will be available in 2007.

\section{Internet for Lawyers online tutorial}

The Virtual Training Suite (VTS), a collection of free subject-based tutorials covering Internet search and research skills, originally formed part of the RDN and is now maintained and updated by Intute. The VTS provides Internet tutorials in over sixty subject areas focused on higher, further and adult education. Subjects range from agriculture, food and forestry, through economic, law and social research methods to veterinary science and women's studies. The tutorials are written by lecturers and librarians with expertise in their subject areas and the Internet. Each tutorial offers an introduction to some of the key Internet sites in its subject area as well as how to avoid some of the common pitfalls of using information found on the web.

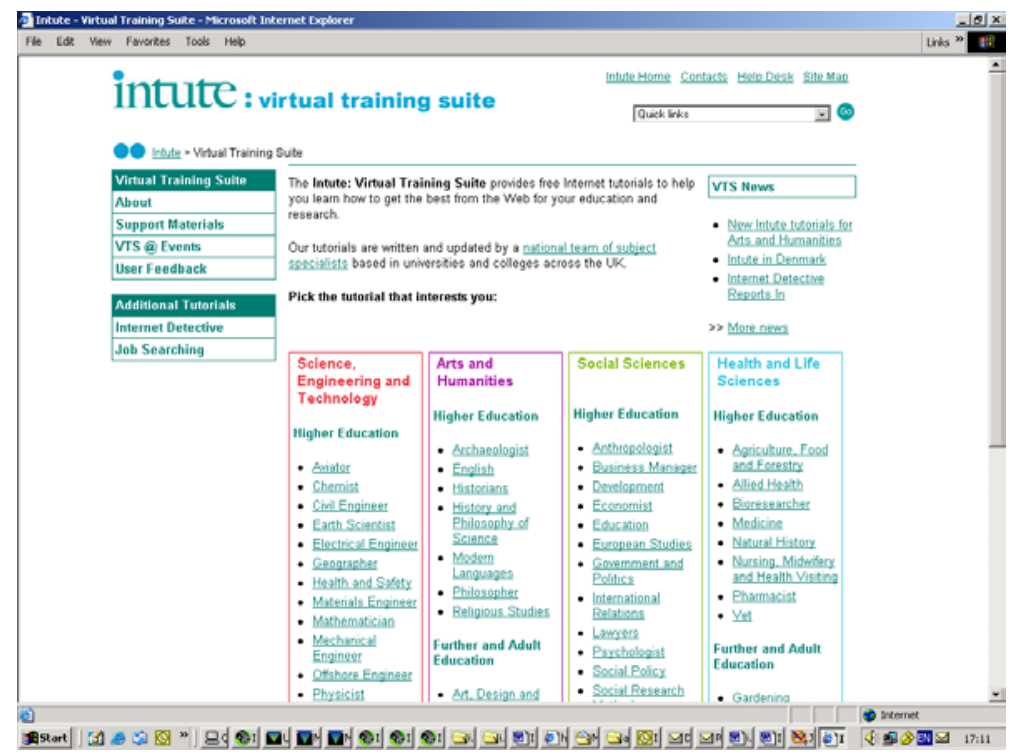


Internet for Lawyers is the online self-paced, interactive legal research tutorial designed for the legal community. The tutorial is written and regularly updated by Sue Pettit, Law Librarian at the Wills Memorial Library University of Bristol. The tutorial focuses on legal materials on the web offering a series of quizzes, exercises and link saving features designed to help develop essential legal Internet research skills. http://www.vts.intute.ac.uk/he/tutorial/lawyers/

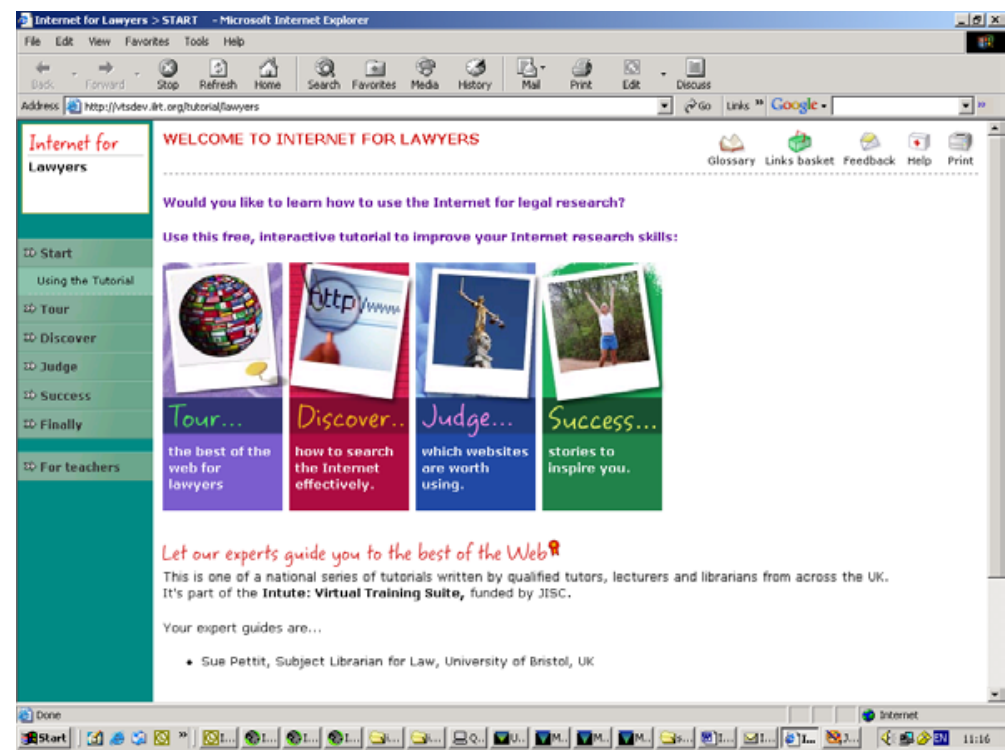

\section{Internet Detective (back on the case !)}

An old favourite called "the Internet Detective", one of the first web-based Internet tutorials, has also been updated and re-launched in June 2006. http://www.vts.intute.ac.uk/detective/

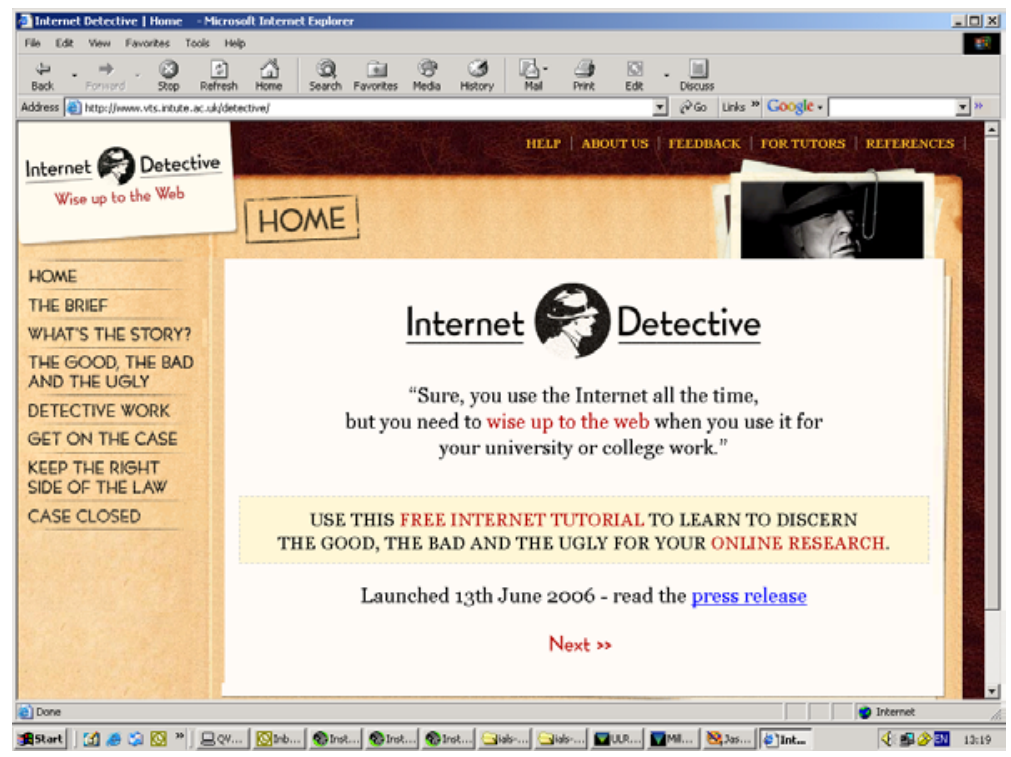

This self-paced tutorial offers general guidance on how to evaluate the quality of Internet-based information, helping you decide on the authority and usefulness of the 
service to your work. Internet Detective offers background information on how the Web works with notes on understanding urls and what they tell us about the identity of the source organisation and country.

\section{Current Awareness}

Intute also offers a number of news and current awareness features to aid legal research. Intute: Behind the Headlines takes topical and current news or subject stories and provides links to relevant areas of the catalogue. Newsround is a news aggregation service, which gathers together a wide range of subject-based newsfeeds from across the Internet and presents them in a single searchable interface. Intute section editors also flag up important subject specific news stories in the Intute Blog at http://www.intute.ac.uk/socialsciences/blog/

\section{Locating Intute in local websites and library catalogues}

Intute supports a number of options for embedding its search facilities in your own working environment http://www.intute.ac.uk/embedding.html

A facility called "Intute-Include" is an application developed to install the Intute search box on your website or Intranet, so you can search Intute remotely, and retrieve results from Intute without leaving your own web environment. Intute-Include is free to the academic community and available to commercial clients for a fee. There is also a version of Intute-Include known as Intute-Lite which provides similar search integration functionality without needing to install any software on your webserver. Results retain the host organisation look and feel, but the result set URL changes to the www.intute.ac.uk domain.

Further information on a range of options for employing Intute-Include is available from http://www.intute.ac.uk/intute-i/index.html

Library catalogue system suppliers have developed portal products and search interfaces that allow access to multiple resources with one search. It makes it possible for a single search to be sent to several selected web-based resources with results presented in a single interface. These products, such as Innovative Interfaces Inc.'s MetaFind on the IALS Library catalogue, facilitate integrated access to Intute. This will allow a single search to trace onsite print materials, electronic subscription resources and free Internet-based resources. Further information on the Intute address for cross search systems is at http://www.intute.ac.uk/z3950.html

System suppliers have also developed products to provide context-sensitive links from the library catalogue to other relevant web-based resources using OpenURL technology. Products, such as Innovative Interfaces Inc.'s WebBridge, enable a catalogue search to be taken forward to a range of other relevant resources. Intute is compatible with such systems and can be included in the resources offered by a library catalogue. Again this new facility will allow researchers to trace library-held print materials or electronic resource subscription services, and go on to find other relevant free remote Internet resources- raising awareness of the full range of available materials.

You can try these features on the IALS Library catalogue at http://ials.sas.ac.uk/catalogue.htm 


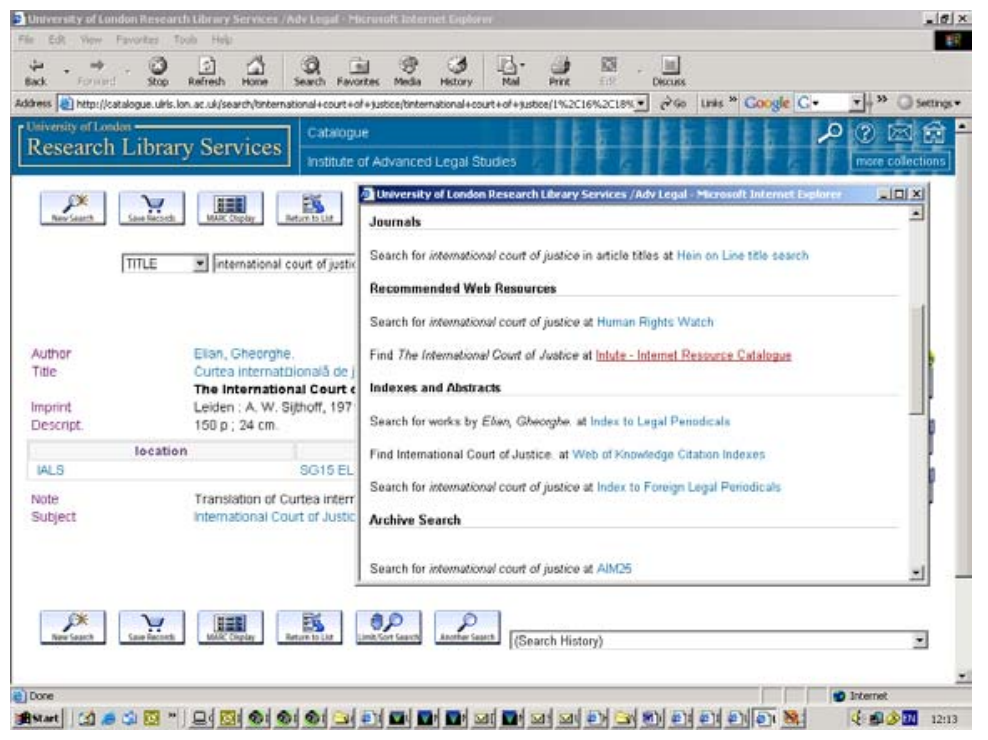

\section{Developing Intute: Law}

As the Internet continues to expand and play an increasingly important role in our lives and work, the Law section editors at the Institute of Advanced Legal Studies and University of Bristol will be working to ensure that Intute: Law is well placed to live up to its name, both guiding users to relevant Internet resources and encouraging selfpaced tutoring in the key skills necessary to get the best from the web.

As you use the service please contact us with comments and suggestions. We'd like to hear from you. How would you like to see the service develop?

More legal subject specialisation? More inter-disciplinary coverage? More international law? More law firm website evaluation?

You can recommend a site for inclusion at any time:

http://www.intute.ac.uk/new resource.html

or contact the Intute: Law Section Editors:

Heather Memess, IALS Library, University of London heather.memess@,sas.ac.uk Sue Pettit, Wills Memorial Library, University of Bristol sue.pettit@bristol.ac.uk Catherine Dack, Wills Memorial Library cath.dack@bristol.ac.uk Steven Whittle, IALS Library, University of London steven.whittle@sas.ac.uk 